\title{
CASHING IN ON SCIENCE
}

University research powers innovation and economic development. Countries with intensive research and development $(R \& D)$ programmes differ in their approach to turning lab studies into commercial enterprises. By Alla Katsnelson, infographic by Mohamed Ashour.

\section{CENTRAL COG}

University research drives the innovation ecosystem by generating inventions, patents and licensing agreements, and by spurring the creation of spin-off companies. The funding for this research comes from multiple sources. Academic researchers also generate income or contribute to knowledge commercialization through contract and collaborative research with companies, as well as through consulting.

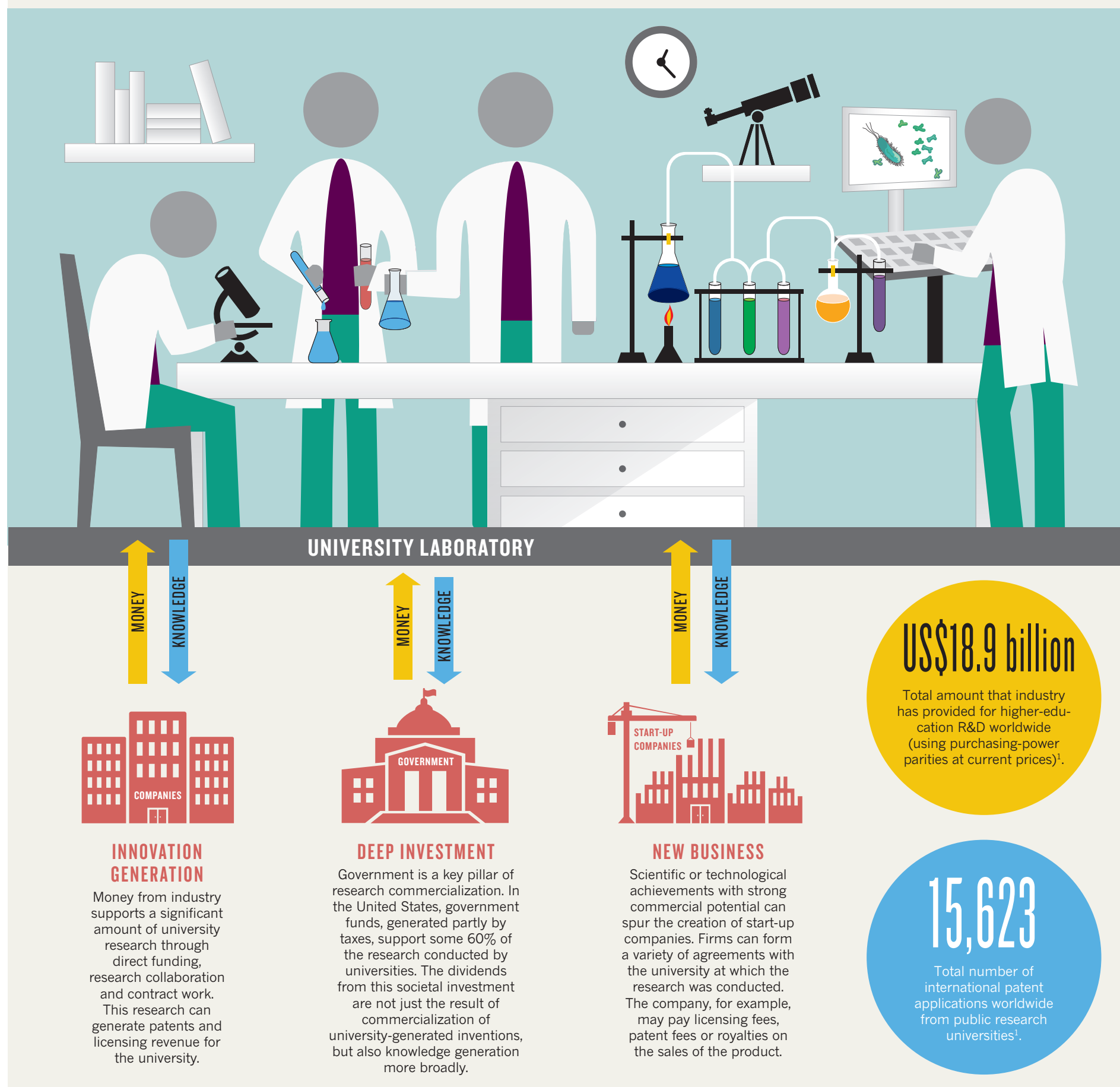




\section{INDUSTRY INFUSION}

Some R\&D conducted at higher-education institutes is financed by companies, China has the highest proportion of industry-financed R\&D. Data are latest available (2012 or 2013) ${ }^{2}$.

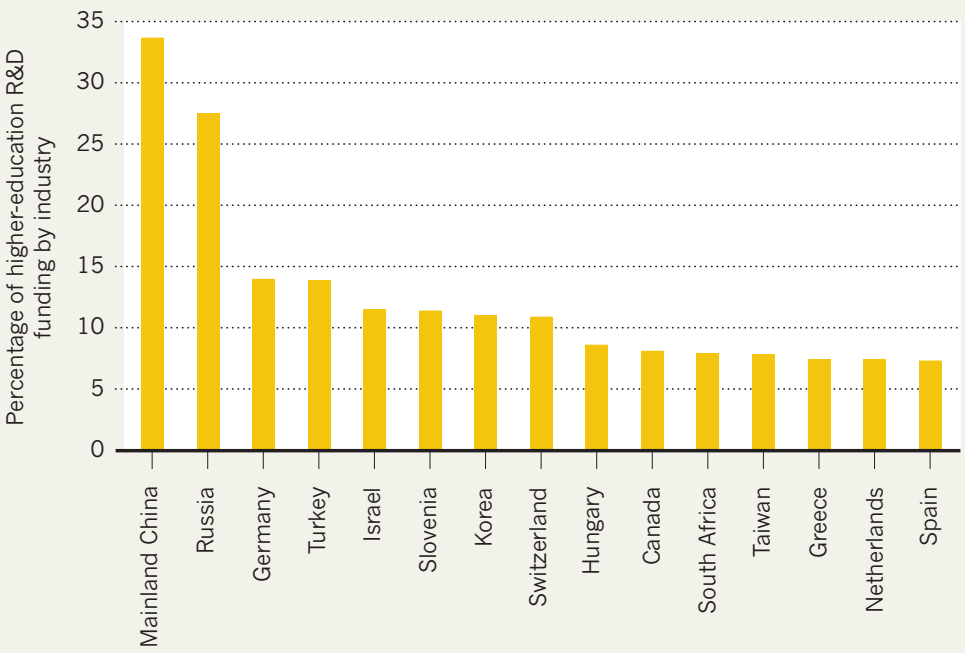

\section{LICENSING TRENDS}

Licensing income from public research fluctuated during the 2007-09 recession, but remained generally stable between 2004 and 2011 . However, only a handful of universities are responsible for the bulk of licensing in each country².

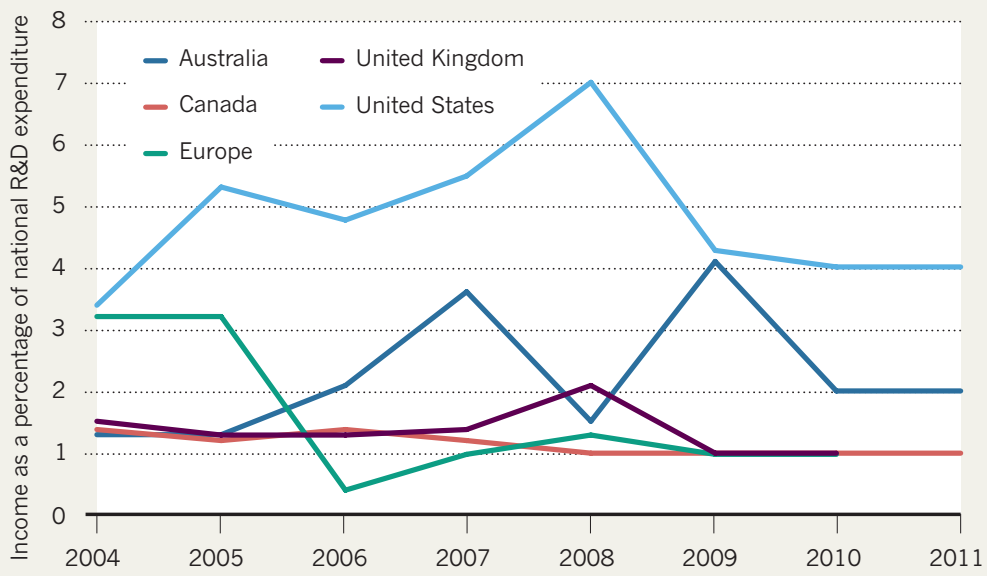

\section{R\&D POWERHOUSES}

US universities have the biggest impact on the development of breakthrough technology ${ }^{3}$ (measured as publications cited by the most highly cited patents - those in the top $10 \%$ of patents cited by other patents).

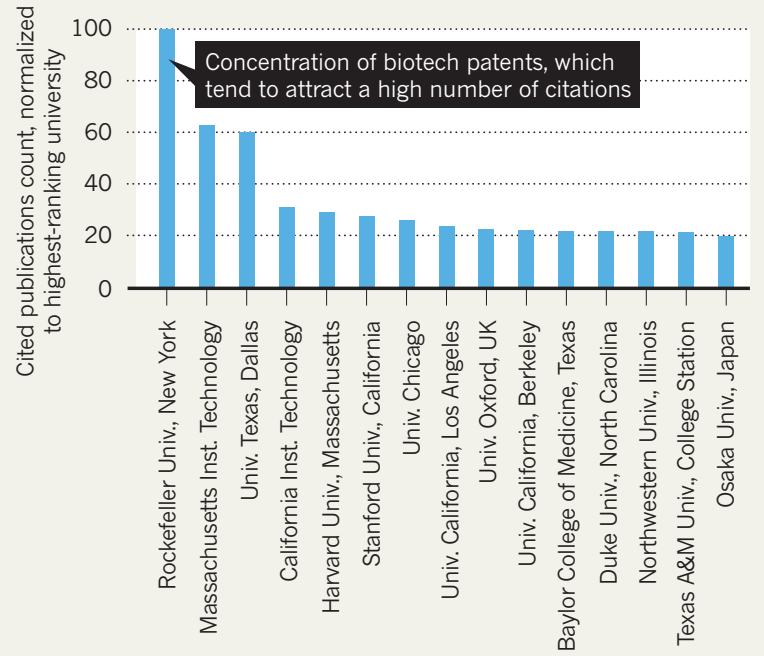

\section{SPUN OFF}

The total number of start-up companies formed from research institutions, including medical centres, in selected countries with a research-commercialization focus. Data are latest available (2013 or 2014)

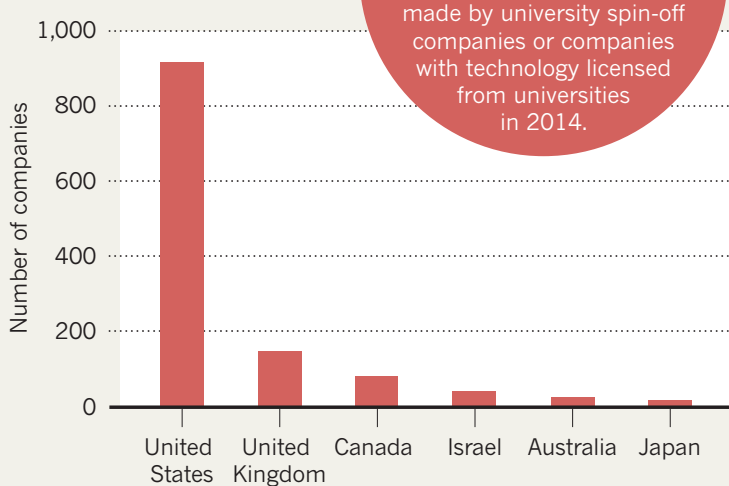

\section{PATENT LANDSCAPE}

In 2014, Israeli public-research institutions filed the highest number of international patent applications, normalized by gross domestic product. How well this metric reflects commercialization, however, varies by country. Inventors may target their patent applications to specific regions and don't always file an international application ${ }^{2}$.

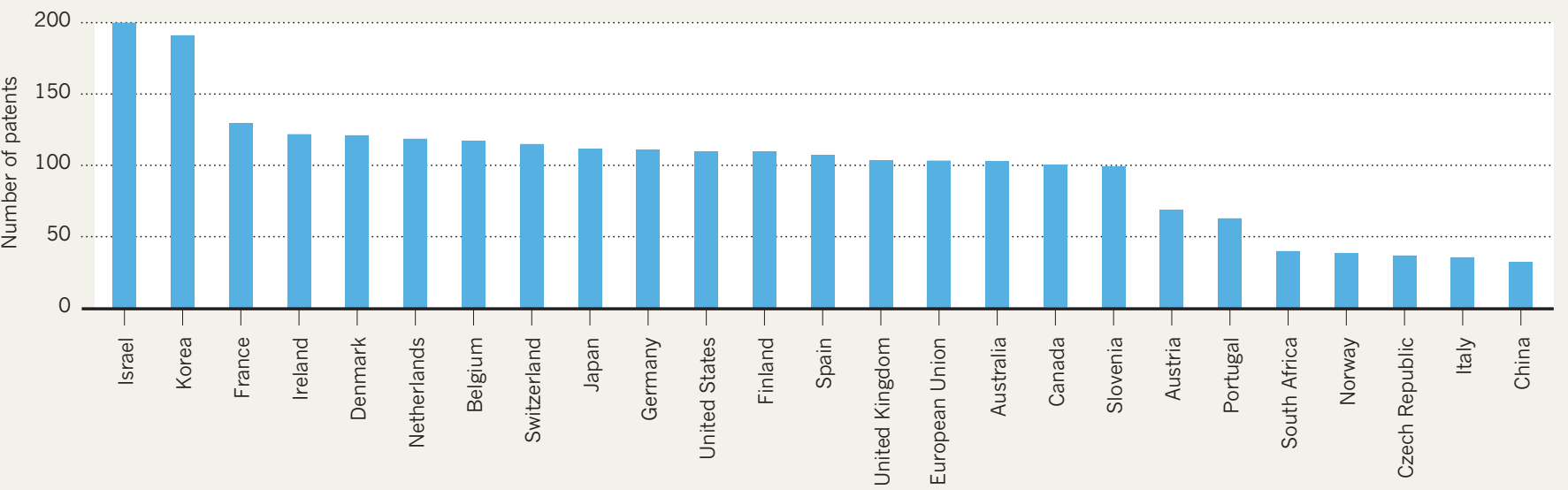

